\title{
Premelting, Pressure Melting, and Regelation of Ice Revisited
}

\author{
Chloe T. Calderon, Pirooz Mohazzabi
}

Department of Mathematics and Physics, University of Wisconsin-Parkside, Kenosha, WI, USA

Email: mohazzab@uwp.edu

How to cite this paper: Calderon, C.T. and Mohazzabi, P. (2018) Premelting, Pressure Melting, and Regelation of Ice Revisited. Journal of Applied Mathematics and Physics, 6, 2181-2191.

https://dx.doi.org/10.4236/jamp.2018.611183

Received: September 26, 2018

Accepted: November 4, 2018

Published: November 7, 2018

Copyright (c) 2018 by authors and Scientific Research Publishing Inc.

This work is licensed under the Creative Commons Attribution International License (CC BY 4.0).

http://creativecommons.org/licenses/by/4.0/

\begin{abstract}
In this article we review some of the most important and relevant literature on the properties of ice. We focus on three of its surface properties, namely, the slipperiness of ice, the phenomena of a string under load passing through a block of ice without cutting the block in half, and pressure melting and adhesion of blocks of ice. We then provide an argument for the most plausible factor responsible for each of these effects.
\end{abstract}

\section{Keywords}

Ice Regelation, Pressure Melting, Quasi-Liquid
Open Access

\section{Introduction}

Perhaps the most interesting solid that we encounter in our everyday life is ice. Ice is one of the few materials in nature with the property of expansion when its liquid form freezes. The cause of this expansion is the formation of a hexagonal ring structure. However, none of the other materials with this property (such as bismuth) are nearly as important in life as water is. Another interesting property of ice is its unusual slipperiness. At the macroscopic level, the coefficient of friction on ice is about one order of magnitude lower than other solid$\mathrm{s}$; however, it is not constant and varies with factors such as sliding speed, temperature, and the normal force [1]. This small coefficien$t$ of friction makes ice even more distinct from other materials since generally the coefficient of kinetic friction increases with temperature, whereas the coefficient of kinetic friction of ice decreases with an increase in temperature [2]. Therefore, one should really compare the coefficient of friction of ice at a few degrees below its melting point to that of other materials when they are also a few degrees below their melting points. The difference would certainly be greater than just one order of magnitude.

Yet another uncommon property that makes ice distinct from other materials is regelation, where two pieces of ice bond when pushed 
together with a fairly small force, and when a string under load passes through an ice block without cutting it in half [3-8].

The question is how the unique behaviors of ice can be explained based on what we know about this solid and its surface properties. In what follows, we describe various behaviors that are specific to ice and, in each case, discuss the reasons that have been given in the existing literature. We then provide, to the best of our judgment, what seems to be the most logical reason for the behavior. But first, let us see what is responsible for the formation of the so called quasi-liquid layer on ice.

\section{The Quasi-Liquid Layer}

Beginning in 1842, Michael Faraday carried out a series of experiments which in 1859 led him to suggest the existence of a "liquid-like" layer on the surface of ice that continues to exist well below its freezing temperature. Although Faraday's idea was ignored for many years, advanced experimental techniques, in recent years, have shown that in fact such liquid-like layer, also known as a "quasi-liquid" layer does indeed exist. Perhaps the most convincing evidence for the existence of such layer are X-ray diffraction studies that show a liquid-like layer on different crystallographic surfaces of ice in the temperature range of $-13.5^{\circ} \mathrm{C}$ to $0^{\circ} \mathrm{C}[9]$. Furthermore, atomic force microscopy has shown that the thickness of this layer at $-24^{\circ} \mathrm{C}$ is about $12 \mathrm{~nm}$, and that surface melting starts at about $-33^{\circ} \mathrm{C}[9,10]$. But Petrenko [11] suggests that pressure melting vanishes at $-22^{\circ} \mathrm{C}$.

Whether this premelting quasi-liquid layer on the surface of ice is a liquid or some disordered phase of ice is not yet completely understood. This disorder structure has been verified by molecular dynamics simulations [9]. However, its physical properties are quite different from that of liquid water. For example, the atomic force microscopy experiments have indicated that the viscosity of this quasi-liquid layer must be two orders of magnitude greater than that of bulk supercooled water $[1,12-14]$. Nevertheless, this premelting layer is not unique to ice [1]. Using ion backscattering from lead crystal, Frenken and van der Veen have concluded that lead has a melting transition of $20^{\circ} \mathrm{C}$ below its bulk melting temperature of $327^{\circ} \mathrm{C}$, and that the thickness of the premelting layer increases logarithmically with temperature $[9,15]$. On the other hand, low energy electron diffraction studies of bismuth, which, similarly to ice, undergoes a negative volume change on melting, indicated no premelting [16].

The phenomenon of surface premelting is not limited to ice [17]. In many solids as the bulk melting temperature is approached, the surface of the solid becomes disordered due to large amplitudes of thermal atomic vibrations. For example, at $-1.8^{\circ} \mathrm{C}$ the mean amplitude of the vibrations of near-surface oxygen atoms in ice exceeds that of the bulk by a factor of $3.3[9,18]$. Because of this, Golecki and Jaccard have suggested that the term "liquid-like" should not even be used [18-20].

In addition to the simple interpretation of disorder of the surface structure near melting point, several other explanations have been given by investigators to explain the liquid-like layer on the ice surface. Ikeda-Fukazawa and Kawamura have suggested that the dangling motion of the free $\mathrm{O}-\mathrm{H}$ bonds at the surface of ice is one of the dominant factors for the surface melting [21]. Another explanation is based on the minimization of surface free energy as a result of formation of a liquid layer [22-25]. The idea of free-energy minimization, however, 
applies to other surfaces as well.

Makkonen, on the other hand, has argued that based on the experimental evidence free-energy minimization is not possible in the case of ice [26]. He then proposes another mechanism for the formation of the liquid-like layer, which is unique for ice. Makkonen's suggestion is based on a concept according to which the surface phase equilibrium temperature differs from that of the bulk. Based on this theory, the imbalance of the molecular forces on the surface molecules results in a pressure difference of $180 \mathrm{MPa}$ between the bulk and the surface of ice, being higher on the surface. This pressure difference lowers the melting point of the surface of ice to $-13^{\circ} \mathrm{C}$. Therefore, at any temperature higher that $-13^{\circ} \mathrm{C}$, the surface of ice is above its melting point as explained in the next section.

\section{Pressure Melting of Ice}

Ice is one of the few solids that undergoes a negative volume change upon melting. Figure 1 shows the pressure-temperature phase diagram for the water system, showing the coexistence curves for each pair of the phases. The slope of each coexistence curve is given by the Clausius-Clapeyron equation [27]

$$
\frac{d P}{d T}=\frac{\Delta H}{T \Delta V}
$$

where $\Delta H$ and $\Delta V$ are the changes of the enthalpy and volume during the transformation, respectively. Because $\Delta H$ and $T$ are both positive, a negative volume change during melting of ice gives $d P / d T<0$, as can be seen in Figure 1 for the ice-water coexistence curve. Therefore, an increase of pressure will decrease the melting temperature of ice, and a decrease of pressure (tension) will increase its melting temperature [6], in accord with the Le Chatelier's principle.

As ice melts, the enthalpy change is $\Delta H=333.5 \mathrm{~kJ} / \mathrm{kg}$, and the densities of ice and water at $0^{\circ} \mathrm{C}$ are, respectively, $916.8 \mathrm{~kg} / \mathrm{m}^{3}$ and $999.8 \mathrm{~kg} / \mathrm{m}^{3}$ [28]. Therefore,

$$
\Delta V=\left(\frac{1}{999.8}-\frac{1}{916.8}\right)=-9.055 \times 10^{-5} \frac{\mathrm{m}^{3}}{\mathrm{~kg}}
$$

Then from Equation (1), we find

$$
\frac{d P}{d T}=\frac{333.5 \times 10^{3}}{273.16\left(-9.055 \times 10^{-5}\right)}=-1.348 \times 10^{7} \frac{\mathrm{Pa}}{\mathrm{K}}=-133 \frac{\mathrm{atm}}{\mathrm{K}}
$$

Therefore, the melting point of ice decreases by $1 \mathrm{~K}$ (or $1^{\circ} \mathrm{C}$ ) for every $133 \mathrm{~atm}$ increase of pressure. Note that since the ice-water coexistence curve in Figure 1 is nearly a straight line, the variation of the melting point with pressure is fairly constant over a wide range of pressures and temperatures.

\section{The Slipperiness of Ice}

The slipperiness of ice, particularly in connection with ice skating and skiing, has been a subject of debate over a very long period of time. In 1886, Joly calculated a pressure of $466 \mathrm{~atm}$ and a corresponding melting point of $-3.5^{\circ} \mathrm{C}$ for ice. Joly suggested that pressure melting was making ice skating possible [9]. But the problem is that the optimum temperature for any sport involving ice skating is considerably lower 


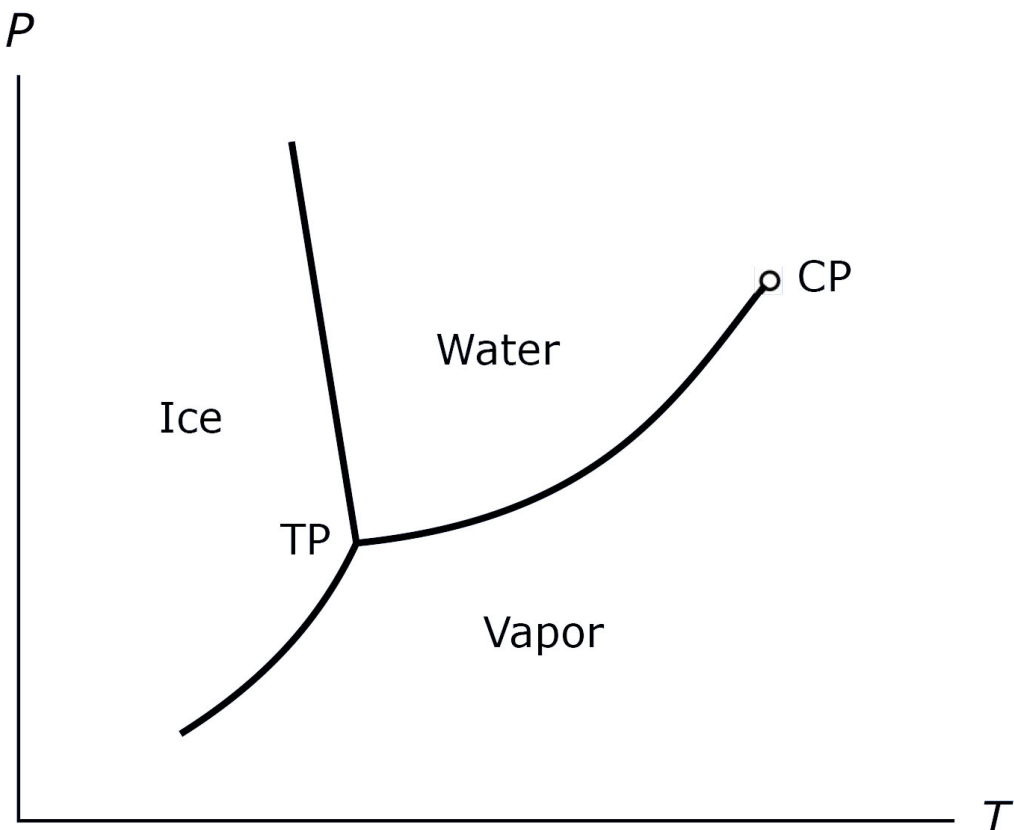

Figure 1. The $P-T$ phase diagram of water system near its triple point (TP). Note that the liquid-vapor coexistence curve terminates at the critical point $(\mathrm{CP})$.

than $-3.5^{\circ} \mathrm{C}$, and that objects as light as a hockey puck can slide just as well [29]. In fact, skating and skiing are possible at temperatures as low as $-35^{\circ} \mathrm{C}$. Therefore, Joly's idea was not supported by the experimental evidence. Nonetheless, pressure melting remained the main explanation for the slipperiness of ice for nearly a century [9].

Years later, it was argued that pressure melting could not be responsible for the low friction of ice [30]. Because the coefficients of friction of metal skis on ice turned out to be higher than those for wood skis, scientists concluded that friction melting was the main reason for the slipperiness of ice at low temperatures, although pressure melting could remain a factor at temperatures near the melting point. A review of relative contributions of each of the mechanisms to the slipperiness of ice, as well as the surface premelting is given by Dash et al. [31].

There is, however, a major logical issue with the concept of friction melting. For heat from the friction to melt the ice, the object must first slide on the ice. Ice does not melt in anticipation of receiving some heat later! Therefore, friction melting as a reason for the slipperiness of ice is not a logical explanation. Consequently, at low temperatures the slipperiness of ice must be mainly due to the premelting quasiliquid layer [1], or a combination of the premelting layer and pressure melting when the temperatures are close to the bulk melting point. In fact, other solids, such as lead. zinc, tin, and cadmium also exhibit lower friction near their bulk melting points [9].

\section{String Passing through the Ice}

It is a well-known experiment that if two heavy masses are attached to the end of a string, and the string is placed over a block of ice, as shown in Figure 2, the string gradually passes through the ice without cutting it in half. This is a situation where pressure melting is the 
sole cause of the process.

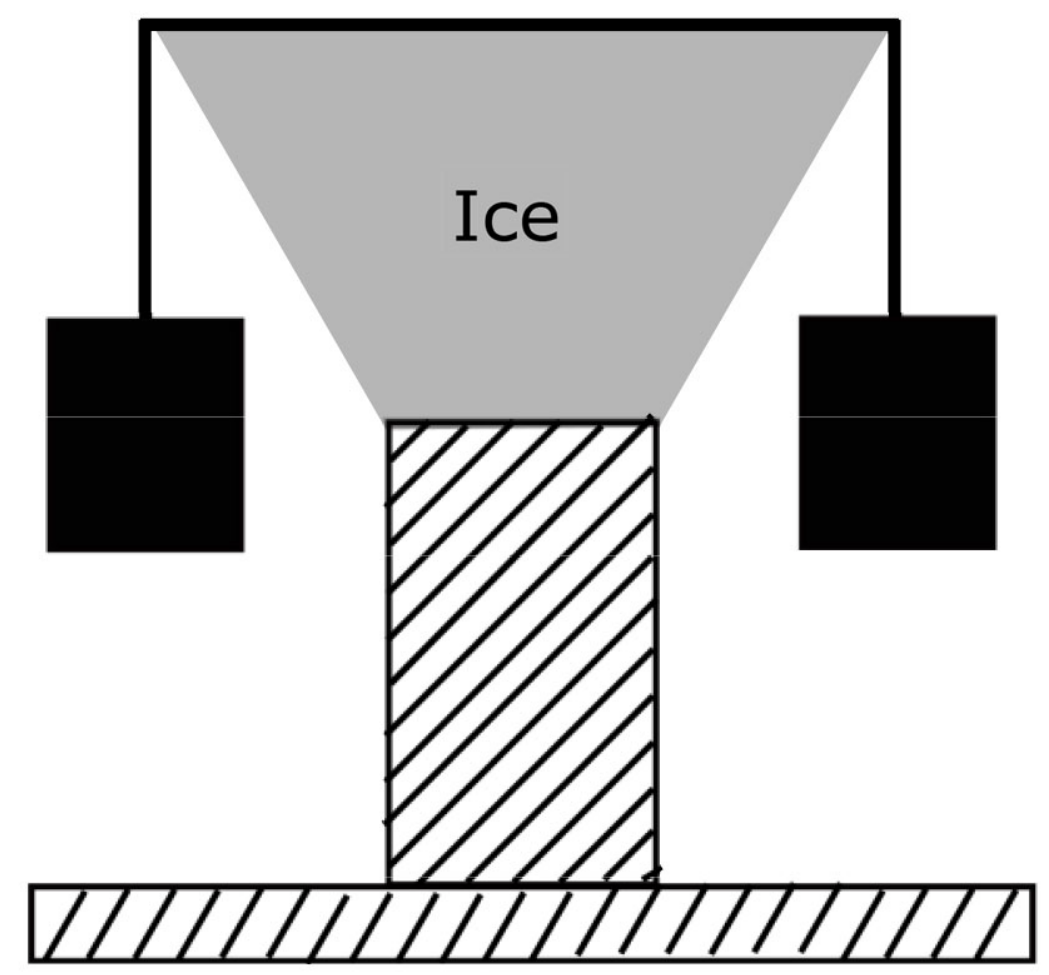

Figure 2. A loaded string gradually passes through the ice without cutting it in half.

Let us consider a wire of length $l=5 \mathrm{~cm}$ and diameter $d=0.5 \mathrm{~mm}$, with hanging masses of $m=2 \mathrm{~kg}$ each. Then the pressure under the wire will be [7]

$$
P=\frac{F}{A}=\frac{2 m g}{l d}=\frac{2(2)(9.80)}{0.05(0.0005)}=1.57 \times 10^{6} \mathrm{~Pa}=15.5 \mathrm{~atm}
$$

Since this pressure is in addition to the existing atmospheric pressure, and for every $133 \mathrm{~atm}$ increase of pressure, the bulk melting point of ice decreases by $1^{\circ} \mathrm{C}$, as explained above, the melting point of the ice under the string decreases to about $-0.12^{\circ} \mathrm{C}$. Admittedly, this change of the melting point is very small. However, since this experiment is normally carried out in an open area under room temperature where the ice is gradually melting, the temperature of the block of ice is very close to $0^{\circ} \mathrm{C}$ and the pressure under the string lowers the melting point enough to cause pressure melting.

As the ice under the string melts, the string moves down slightly, and the liquid water moves to the top of the string where the high pressure no longer exists, and it freezes. As these steps are continuously repeated, the string passes through the ice without cutting it in half. However, during the process heat transfer should take place across the diameter of the wire. As ice melts under the string, it absorbs heat $(\Delta H=79.7 \mathrm{cal} / \mathrm{g})$ [5]. Then when it refreezes at the top of the string, it releases the heat. This heat must now be transferred across the diameter of the string to its lower part. Therefore, a thermally conducting string (such as copper) should pass through the ice faster than a nonconducting string (such as nylon) assuming the same 
diameters and hanging masses. This, in fact, has been very clearly demonstrated experimentally $[4,32]$. In these experiments, however, the outside sections of the wire should be well insulated to avoid heat transfer into the ice from outside [7].

\section{Adhesive Properties of Ice}

The first systematic investigation into adhesion of blocks of ice together started in 1842 by Michael Faraday. Faraday observed that when two moist blocks of ice are placed into contact even with a small force, they would stick together [33]. He attributed this phenomenon to the existence of a liquid-like layer on the surface of ice. In 1848, James Thomson explained Faraday's experiment using pressure melting. His idea was that ice would melt under external pressure due to lowering of the equilibrium melting point and then refreezes when the pressure is removed [33]. Despite the fact that some references claim pressure melting cannot be responsible for regelation of ice blocks [26, 33, 34], in what follows we argue that in fact both Faraday and Thomson were correct and that pressure melting and the quasi-liquid layer are both responsible for the phenomenon depending on the temperature.

The argument against pressure melting when two block of ice stick together under a small force is that even at a temperature slightly below the melting point, very large pressures are needed to premelt the ice. To dispute this argument, consider two moist blocks of ice that are brought in contact with a small force, say $1 \mathrm{~N}$, and let the apparent area of contact between them be $1 \mathrm{~cm}^{2}$. Like any other material, the surface of ice is very rough due to asperities, as determined by atomic force microscopy (AFM) [10] and scanning force microscopy (SFM) and force curves (FC) [11]. In fact, it is known that the actual area of contact due to asperities can be $10^{4}$ times smaller than the apparent area of contact [35]. This can generate a pressure of about $100 \mathrm{MPa}$ or $987 \mathrm{~atm}$ at the contact area, which lowers the melting point of ice to $-7.4^{\circ} \mathrm{C}$. But since there is moisture on the surface of the ice cubes, they are in thawing state and their temperatures are slightly below $0^{\circ} \mathrm{C}$. As a result, the ice premelts under this pressure at the contact point and refreezes when the pressure is removed. Therefore, Thomson's explanation was correct.

A question that one might ask is does the moisture on the surface of ice play any role other than ensuring that the surface temperature of the ice is close to thawing conditions? For example, is the moisture required because when ice undergoes pressure melting at the asperities and absorbs heat from the surrounding moisture it causes the moisture to freeze? To answer these questions, we performed two experiments. In one experiment, we submerged two blocks of ice that were at the thawing stage in a saturated saline solution (freezing point $-21^{\circ} \mathrm{C}$ ), and in the other experiment we submerged them in isopropyl alcohol (freezing point $-89^{\circ} \mathrm{C}$ ). We then stirred the liquids for about a minute, and then brought the ice blocks together with a small force. In each case the blocks adhered together. Therefore, the role of the moisture is to ensure that the temperature is only slightly below the bulk freezing point of the ice.

The second factor for the adhesiveness of ice is the existence of the premelting quasi-liquid layer on its surface, which persists to temperatures far below its bulk melting point. As stated earlier, according to Makkonen [26] the formation of this layer is due to a higher surface pressure of about $180 \mathrm{MPa}$ compared to the bulk and, therefore, the 
surface phase equilibrium temperature of ice differs from that of its bulk. This pressure difference is caused by imbalance of the molecular forces on the surface molecules and, consequently, the surface melting temperature is reduced to $-13^{\circ} \mathrm{C}$.

Now suppose that two blocks of ice are brought into slight contact, as shown in Figure 3. The quasi-liquid layer on each block is under a pressure of $180 \mathrm{MPa}$ higher than the bulk. These pressures are also shown in the figure. When the two blocks make contact, at the contact point these pressures cancel out, hence the molecular forces become balanced and the quasi-liquid layer freezes. Therefore, Faraday's reasoning that the liquid-like layer is responsible for regelation of ice was also correct. To this end, we mention that several results predicted by the Makkonen's theory are in quantitative agreement with experimental data.

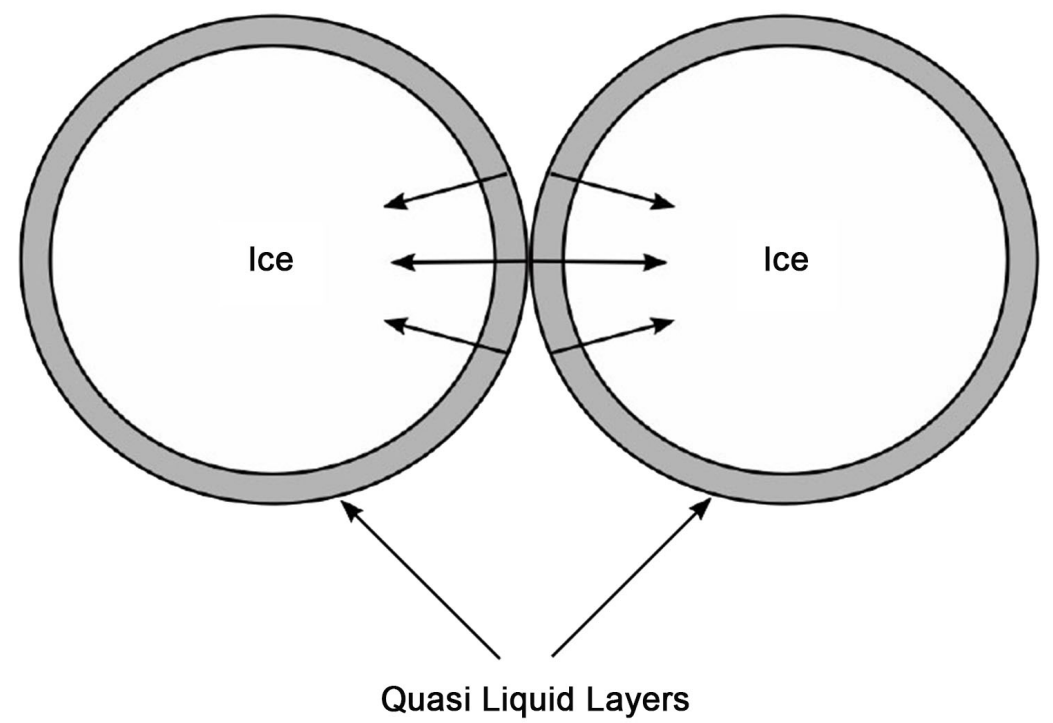

Figure 3. A schematic diagram showing cancellation of surface pressures on quasi-liquid layers when two pieces of ice are brought together.

Finally, out of curiosity we placed two blocks of ice in liquid nitrogen. After thermal equilibration, we pushed them together for several minutes with large enough force to cause the ice blocks crumble. We observed that the blocks of ice did not adhere together. This is because at the liquid nitrogen temperature $\left(-196^{\circ} \mathrm{C}\right)$ there is no quasi-liquid layer on ice and the pressures required for its pressure melting is $\mathrm{u}-$ nimaginable.

\section{Summary}

Ice has two unique properties. First, it is the only solid that we ordinarily encounter in our everyday life that is only a few degrees below its melting point. Under normal conditions, other solids are usually very far from their melting points. Second, ice is one of the few solids that contracts on melting, therefore, can undergo pressure melting. These characteristics of ice are responsible for many of its interesting properties.

The first and, perhaps, the most important property of ice is its slipperiness or low coefficient of friction. Although various reasons have been suggested to explain this effect, each has their strengths 
and weaknesses. However, it seems that existence of the quasi-liquid layer on the surface of ice is the most plausible reason, especially since some other solids exhibit low coefficients of friction near their melting points as well.

The phenomenon in which a loaded string passes through a block of ice without cutting it in half is solely due to pressure melting of the ice. The pressure caused by the string lowers the bulk melting point of the ice and, as a result, if the temperature of the ice is only slightly below its freezing point, it melts. The water thus formed moves to the top of the string and refreezes.

Finally, when two moist blocks of ice are brought together even with a small force, they adhere together. This phenomenon was originally explained by Faraday and Thomson using two different factors: existence of the quasi-liquid layer and pressure melting, respectively. As we have argued in this article, both mechanisms are correct and can contribute to the process.

\section{Acknowledgements}

This work was supported by a URAP grant from the University of Wisconsin-Parkside.

\section{Conflicts of Interest}

The authors declare no conflicts of interest regarding the publication of this paper.

\section{References}

[1] Li, Y.M. and Somorjai, G.A. (2007) Surface Premelting of Ice. The Journal of Physical Chemistry, 111, 9631-9637. https://doi.org/10.1021/jp071102f

[2] Kauffman, P. and Vondracek, M. (2005) The Effect Surface Temperature Has on Kinetic Friction. The Physics Teacher, 43, 173175.

https://doi.org/10.1119/1.1869429

[3] Hilton, W.A. (1974) Apparatus for Teaching Physics: Ice Cube Regelation. The Physics Teacher, 307-308. https://doi.org/10.1119/1.2350388

[4] Pryor, M.J. (1966) Apparatus for Teaching Physics: Regelation Is for Everybody. The Physics Teacher, 4, 368-369. https://doi.org/10.1119/1.2351051

[5] Zemansky, M.W. (1965) The Regelation of Ice Is a Complicated Phenomenon. The Physics Teacher, 3, 301-302.

https://doi.org/10.1119/1.2349163

[6] Sun, C.Q. Regelation: Why Does Ice Melt Under Pressure? https://arxiv.org/ftp/arxiv/papers/1501/1501.06981.pdf

[7] Mohazzabi, P. (2011) The Physics of "String Passing Through Ice". The Physics Teacher, 49, 429-431. https://doi.org/10.1119/1.3639152

[8] Hynninen, T., Heinonen, V., Dias, C.L., Karttunen, M., Foster, A.S. and Ala-Nissila, T. (2010) Cutting Ice: Nanowire Regelation. 
Physical Review Letters, 105, Article ID: 086102.

https://doi.org/10.1103/PhysRevLett.105.086102

[9] Rosenberg, R. (2005) Why Is Ice Slippery? Physics Today, 58, 50-55.

[10] Döppenschmidt, A., Kappl, M. and Butt, H.-J. (1998) Surface Properties of Ice Studied by Atomic Force Microscopy. The Journal of Physical Chemistry B, 102, 7813-7819.

https://doi.org/10.1021/jp981396s

[11] Petrenko, V.F. (1997) Study of the Surface of Ice, Ice/Solid and Ice/Liquid Interfaces with Scanning Force Microscopy. The Journal of Physical Chemistry B, 101, 6276-6281.

https://doi.org/10.1021/jp963217h

[12] Pittenger, B. (1998) Erratum: Investigation of Ice-Solid Interfaces by Force Microscopy: Plastic Flow and Adhesive Forces [J. Vac. Sci. Technol. A16, 1832 (1998)]. Journal of Vacuum Science Technology A, 16, 3582-3582.

https://doi.org/10.1116/1.581002

[13] Butt, H.J. (2000) Analysis of Plastic Deformation in Atomic Force Microscopy: Application to Ice. The Journal of Chemical Physics, 113, 1194-1203. https://doi.org/10.1063/1.481898

[14] Pittenger, B., Fain Jr., S.C., Cochran, M.J., Donev, J.M.K., Robertson, B.E., Szuchmacher, A. and Overney, R.M. (2001) Premelting at Ice-Solid Interfaces Studied via Velocity-Dependent Indentation with Force Microscope Tips. Physical Review B, 63, Article ID: 134102 .

https://doi.org/10.1103/PhysRevB.63.134102

[15] Frenken, J.W.M. and van der Veen, J.F. (1985) Observation of Surface Melting. Physical Review Letters, 54, 134. https://doi.org/10.1103/PhysRevLett.54.134

[16] Goodman, R.M. and Somorjai, G.A. (2003) Low-Energy Electron Diffraction Studies of Surface Melting and Freezing of Lead, Bismuth, and Tin Single-Crystal Surfaces. Journal of Chemical Physics, 52, 6325.

https://doi.org/10.1063/1.1672946

[17] Wettlaufer, J.S. and Worster, M.G. (2006) Premelting Dynamics. Annual Review of Fluid Mechanics, 38, 427-452. http://www.itg.cam.ac.uk/people/grae/68.pdf

[18] Petrenko, V.F. (1994) The Surface of Ice. US Army Corps of Engineers: Cold Regions Research \& Engineering Laboratory, Special Report 94-22, August 1994.

[19] Golecki, I. and Jaccard, C. (1977) The Surface of Ice Near $0^{\circ} \mathrm{C}$ Studied by $100 \mathrm{keV}$ Proton Channeling. Physical Letters A, 63, 374-376.

https://doi.org/10.1016/0375-9601(77)90936-7

[20] Golecki, I. and Jaccard, C. (1978) Intrinsic Surface Disorder in Ice Near the Melting Point. Journal of Physics C: Solid State Physics, 11, 4229-4237.

https://doi.org/10.1088/0022-3719/11/20/018 
[21] Ikeda-Fukazawa, T. and Kawamura, K. (2004) MolecularDynamics Studies of Surface of Ice Ih. Journal of Chemical Physics, 120, 1395-1401.

https://doi.org/10.1063/1.1634250

[22] Takagi, S. (1990) Approximate Thermodynamics of the LiquidLike Layer on an Ice Sphere Based on an Interpretation of the Wetting Parameter. Journal of Colloid and Interface Science, 137, 446-455.

https://doi.org/10.1016/0021-9797(90)90419-O

[23] Jellinek, H.H.G. (1967) Liquid-Like (Transition) Layer on Ice. Journal of Colloid and Interface Science, 25, 192-205. https://doi.org/10.1016/0021-9797(67)90022-7

[24] Dash, J.G. (1989) Thermomolecular Pressure in Surface Melting: Motivation for Frost Heave. Science, 246, 1591-1593. https://doi.org/10.1126/science.246.4937.1591

[25] Baker, M.B. and Dash, J.G. (1989) Charge Transfer in Thunderstorms and the Surface Melting of Ice. Journal of Crystal Growth, 97, $770-776$. https://doi.org/10.1016/0022-0248(89)90581-2

[26] Makkonen, L. (1997) Surface Melting of Ice. Journal of Physical Chemistry B, 101, 6196-6200. https://doi.org/10.1021/jp963248c

[27] Zemansky, M.W. and Dittman, R.H. (1997) Heat and Thermodynamics. 7th Edition, McGraw-Hill, New York, 286-292.

[28] Silbey, R.J. and Alberty, R.A. (2001) Physical Chemistry. 3rd Edition, Wiley, New York, 182-183.

[29] Haché, A. (2008) A Cool Sport Full of Physics. The Physics Teacher, 46, 398-402. https://doi.org/10.1119/1.2981284

[30] Colbeck, S.C. (1995) Pressure Melting and Ice Skating. American Journal of Physics, 63, 888-890. https://doi.org/10.1119/1.18028

[31] Dash, J.G., Fu, H. and Wettlaufer, J.S. (1995) The Premelting of Ice and Its Environmental Consequences. Reports on Progress in Physics, 58, 115.

https://doi.org/10.1088/0034-4885/58/1/003

[32] Drake, L.D. and Shreve, R.L. (1973) Pressure Melting and Regelation of Ice by Round Wires. Proceedings of the Royal Society of London A, 332, 51-83.

https://doi.org/10.1098/rspa.1973.0013

[33] Hobbs, P.V. (1974) Ice Physics. Chap. 6, Oxford University Press, Oxford.

[34] Nakaya, U. and Matsumoto, A. (1954) Simple Experiment Showing the Existence of "Liquid Water" Film on the Ice Surface. Jouran of Colloid Science, 9, 41-49. https://doi.org/10.1016/0095-8522(54)90084-7 
[35] Krim, J. (2002) Resource Letter: FMMLS-1: Friction at Macroscopic and Microscopic Length Scales. American Journal of Physics, 70, 890-897.

https://doi.org/10.1119/1.1484153 